\title{
Editorial note for the special issue: ECPA 2019
}

\author{
J. Lowenberg-DeBoer ${ }^{1}$
}

Published online: 8 March 2021

(c) The Author(s), under exclusive licence to Springer Science+Business Media, LLC, part of Springer Nature 2021

The 12th European Conference on Precision Agriculture (ECPA 2019), was held in Montpellier, France 8-11 July, 2019. For the ECPA, this was the first return to France since the 3rd ECPA was held in Montpellier in 2001. It was attended by 380 participants from 37 countries who witnessed 124 oral presentations and examined 84 posters which covered the full range of disciplines, crops and agro-ecological environments where precision agriculture is practiced. Precision Agriculture invited submissions of enhanced manuscripts from the 12th ECPA with additional results and analysis for this special issue. The 14 articles published here were subject to the usual rigorous review and editing that all Precision Agriculture manuscripts under go. The authors come from five European countries, plus the USA, Australia, Colombia and Israel showing the wide European and international reach of the conference.

The ECPA is one of five precision agriculture conferences organized under the auspices of the International Society of Precision Agriculture (ISPA). The others are: the AsianAustralasian Conference on Precision Agriculture (ACPA), the Latin American Conference on Precision Agriculture (Spanish Acronym is CLAP), the African Conference on Precision Agriculture (AfCPA) and the International Conference on Precision Agriculture (ICPA). Only the ECPA has gone on to provide enhanced research results and analysis for a Precision Agriculture special issue as a group, but research presented at the other conferences is one of the main sources of manuscripts submitted to the journal.

Of the 14 articles in this special issue, 4 report on research in precision viticulture, reflecting the importance of vineyards in European agriculture and the growth of precision viticulture. The papers in this special issue focus on water management and automated sensing of vineyard conditions. Bellvert et al. report on a profitable and water saving irrigation decision support system that uses satellite remote sensing images to create irrigation water application zones. Oger et al. describe an improved system to estimate grape bunch yields using targeted sampling and within-field route optimization. Marani et al. focus on detection of grape bunches in red-green-blue (RGB) photographs with the goal of improving grape yield estimation and assessment of phenotypic traits. They take on the particularly challenging case of white grapes which blend in with the surrounding foliage. Pichon et al. summarize experience with a mobile phone application that allows users to

J. Lowenberg-DeBoer

jlowenberg-deboer@harper-adams.ac.uk

1 Land, Farm and Agribusiness Management Department, Harper Adams University, Newport, Shropshire, UK 
characterize the vineyard water stress in their own fields and compare them with that of others in the region.

Because water availability is a key condition for plant growth, five articles focus on monitoring water stress and irrigation management. The Bellvert et al. and Pichon et al. articles report on technologies to improve water management in vineyards. Vories et al. focus on allocating irrigation water for cotton using soil texture mapped with electrical conductivity and irrigation scheduling based on weather and soil temperature sensors. Jimenez et al. apply neural network machine learning tools to data from a network of soil sensors to improve irrigation water management for cotton. Klapp et al. combine thermal remote sensing convolutional neural network analysis to monitor crop water status for a vineyard, peach orchard and several cotton fields.

Nitrogen is an essential plant nutrient that is the focus of two of the special issue studies. Argento et al. analyse the use of images gathered by unmanned aerial vehicles (UAVs) to improve in-season management of nitrogen fertilizer on-wheat in small fields in Switzerland. In contrast Trevisan et al. use spatially weighted regression with on-farm trial data to estimate maize response to nitrogen and seeding rates, with the hope of improving management in future seasons.

All of the special issue articles use data from either equipment mounted, proximate or remote sensing. Klapp et al. and Oger et al. use remotely sensed data gathered with piloted aircraft. Fajardo and Whelan used satellite remote sensing images to improve within-farm wheat yield estimates using machine learning algorithms. Bellvert et al. also used satellite imagery. Argento et al. employed data from a UAV. Trevisan et al. used data from equipment mounted input and output sensors (i.e. yield maps, seed as applied maps and nitrogen as applied maps). Vories et al. and Buttafuoco et al. used electrical conductivity mapping in addition to other data. Gée et al., Pichon et al. and Emmi et al. used RGB camera images as well as other sensors. Jimenez et al. use a network of soil water sensors and Bönecke et al. used on-the-go soil nutrient sensors.

This special issue was made possible by the collaborative effort of co-editors-in-chief John Stafford and James Lowenberg-DeBoer, with the help of numerous ad hoc reviewers. The co-editors-in-chief are grateful for the effort of Dr. Bruno Tisseyre and his team for organizing ECPA 2019, and reviewing the abstracts and papers submitted for the conference. That initial review laid the foundations for the excellence of the enhanced manuscripts eventually published.

This special issue is a valuable resource for researchers and practitioners of precision agriculture around the world. It shows the state of the art in multiple domains including machine learning, analysis of remote sensing data, and development of decision support for irrigation and other input management. It is hoped that these articles will generate intense discussion and lay the basis for the next iteration of progress toward the precision agriculture goal of improving spatial and temporal management of agriculture for economic and environmental goals.

Publisher's Note Springer Nature remains neutral with regard to jurisdictional claims in published maps and institutional affiliations. 